\title{
Approaches to improve adherence to pharmacotherapy in patients with schizophrenia
}

\author{
This article was published in the following Dove Press journal: \\ Patient Preference and Adherence \\ 14 May 2014 \\ Number of times this article has been viewed
}

\section{Kimberly M Shuler}

Shuler Counseling and Consulting, Fayetteville, AR, USA
Correspondence: Kimberly M Shuler Shuler Counseling and Consulting,

22I North East Street - Suite 206,

Fayetteville, AR 7270I, USA

Tel +I 479200 7I 57

Email shuler.kim@gmail.com
Purpose: In patients with schizophrenia, nonadherence to prescribed medications increases the risk of patient relapse and hospitalization, key contributors to the costs associated with treatment. The objectives of this review were to evaluate the impact of nonadherence to pharmacotherapy in patients with schizophrenia as it relates to health care professionals, particularly social workers, and to identify effective team approaches to supporting patients based on studies assessing implementation of assertive community treatment teams.

Materials and methods: A systematic review of the medical literature was conducted by searching the Scopus database to identify articles associated with treatment adherence in patients with schizophrenia. Articles included were published from January 1, 2003, through July 15, 2013, were written in English, and reported findings concerning any and all aspects of nonadherence to prescribed treatment in patients with schizophrenia.

Results: Of 92 unique articles identified and formally screened, 47 met the inclusion criteria for the systematic review. The burden of nonadherence in schizophrenia is significant. Factors with the potential to affect adherence include antipsychotic drug class and formulation, patient-specific factors, and family/social support system. There is inconclusive evidence suggesting superior adherence with an atypical versus typical antipsychotic or with a long-acting injectable versus an oral formulation. Patient-specific factors that contribute to adherence include awareness/ denial of illness, cognitive issues, stigma associated with taking medication, substance abuse, access to health care, employment/poverty, and insurance status. Lack of social or family support may adversely affect adherence, necessitating the assistance of health care professionals, such as social workers. Evidence supports the concept that an enhanced team-oriented approach to managing patients with schizophrenia improves adherence and supports corresponding reductions in relapse rates, inpatient admissions, and associated costs.

Conclusion: Optimization of medication and involvement of caregivers are important to promoting adherence. A multidisciplinary team approach may be invaluable in identifying barriers to adherence and helping schizophrenia patients overcome them.

Keywords: medication adherence, schizophrenia, community mental health services, social work, psychiatric

\section{Introduction}

A common barrier that precludes health care professionals from helping patients achieve their treatment goals is poor patient adherence to prescribed treatment. Survey data from psychiatrists treating patients with schizophrenia suggest that more than two thirds of patients exhibit at least some level of nonadherence to prescribed medications. ${ }^{1}$ The most prominent patient-related factors associated with nonadherence in the survey included lack of insight into the need for medication, denial of 
illness, embarrassment, and unsuitable living conditions for compliance. In a patient survey study that was conducted by nurses, the two most prominent barriers to medication adherence were stigma associated with taking medication and adverse drug reactions. ${ }^{2}$ Evidence also suggests that a variety of other factors may play a role in pharmacotherapy nonadherence among patients with schizophrenia, including the drug class prescribed (ie, typical versus atypical antipsychotics), ${ }^{3-5}$ drug formulation (ie, oral versus long-acting injectable [LAI] formulation), ${ }^{6}$ lack of adequate social support, ${ }^{7}$ lack of access to health care, ${ }^{8}$ and concurrent substance abuse. ${ }^{9}$ In patients with schizophrenia, nonadherence to prescribed medication is associated with symptom relapse, increased hospitalizations, and increased health care costs. ${ }^{10,11}$

Given the prevalence and impact of medication nonadherence, it is important for health care professionals to understand patient barriers to treatment adherence and to be familiar with multidisciplinary treatment-team approaches to overcome these barriers. This article reviews the burden of medication nonadherence among patients with schizophrenia and factors influencing nonadherence, which are critical elements to consider when identifying treatment approaches to optimize schizophrenia patient outcomes. This article also reviews the elements of a multidisciplinary treatment-team approach to optimize treatment adherence. Integrated, multidimensional team approaches to managing patients with schizophrenia - most notably by an assertive community treatment (ACT) team - may help improve adherence and optimize patient outcomes. One of the key principles of ACT team care is medication management, ${ }^{12}$ which has the potential to positively affect outcomes associated with nonadherence.

\section{Materials and methods Objectives and design}

The first objective of this systematic review was to evaluate the burden of nonadherence to pharmacotherapy in patients with schizophrenia and to identify different factors that may influence nonadherence as they relate to the functions of health care professionals, particularly social workers. In an effort to summarize how and when team members can play a role in helping patients overcome nonadherence, the second objective was to evaluate outcomes from studies in which ACT teams have been implemented and identify effective team approaches to support patients with schizophrenia.

Meta-analyses of primary data were not performed; descriptive summaries of identified articles are provided, with a focus on primary adherence data or adherence-related outcomes/findings. The review was developed using the framework established by the Preferred Reporting Items for Systematic Reviews and Meta-Analyses guidelines. ${ }^{13}$

\section{Literature search and article selection}

All articles selected for inclusion were published between January 1, 2003, and July 15, 2013; all articles were published in English. Articles were identified by searching the Scopus database (http://www.scopus.com/home.url) using the following search terms: search 1 - ("adherence" OR "compliance") AND "schizophrenia" AND ("social work" OR "social worker" OR “case manager"); search 2 - "schizophrenia" AND ("assertive community treatment team" OR "ACT team"). Reference lists from articles that were identified using these search terms were also manually searched to identify additional relevant articles that may not have been captured in the original searches; publication date limits imposed on the Scopus search were not employed in the manual search of reference lists.

All articles included in the review were required to present original clinical research, database analyses, survey data, or systematic review findings concerning any and all aspects of nonadherence to prescribed treatment in patients with schizophrenia. There were no restrictions with regard to study designs or types of interventions. All patient-specific data had to have originated from individuals described as having schizophrenia or psychosis. Survey data from nonpatients were permitted, provided that the analysis included direct relevance to nonadherence in patients with schizophrenia or psychosis. All case studies and nonsystematic reviews were excluded.

\section{Results \\ Search results}

Search 1 identified 28 articles, of which eleven were considered relevant. Search 2 identified 31 articles, of which two were considered relevant. Manually searching article reference lists identified an additional 34 relevant articles for inclusion (47 total articles included in the review; Figure 1). In the original searches, emphasis was placed on references that considered adherence from the perspective of the social worker or ACT team member. Given the small number of articles identified using the prespecified search terms, the manual search of reference lists of articles identified in the original searches was inclusive of well-designed studies addressing adherence from a broader perspective. Articles selected for inclusion are summarized in Table 1. 


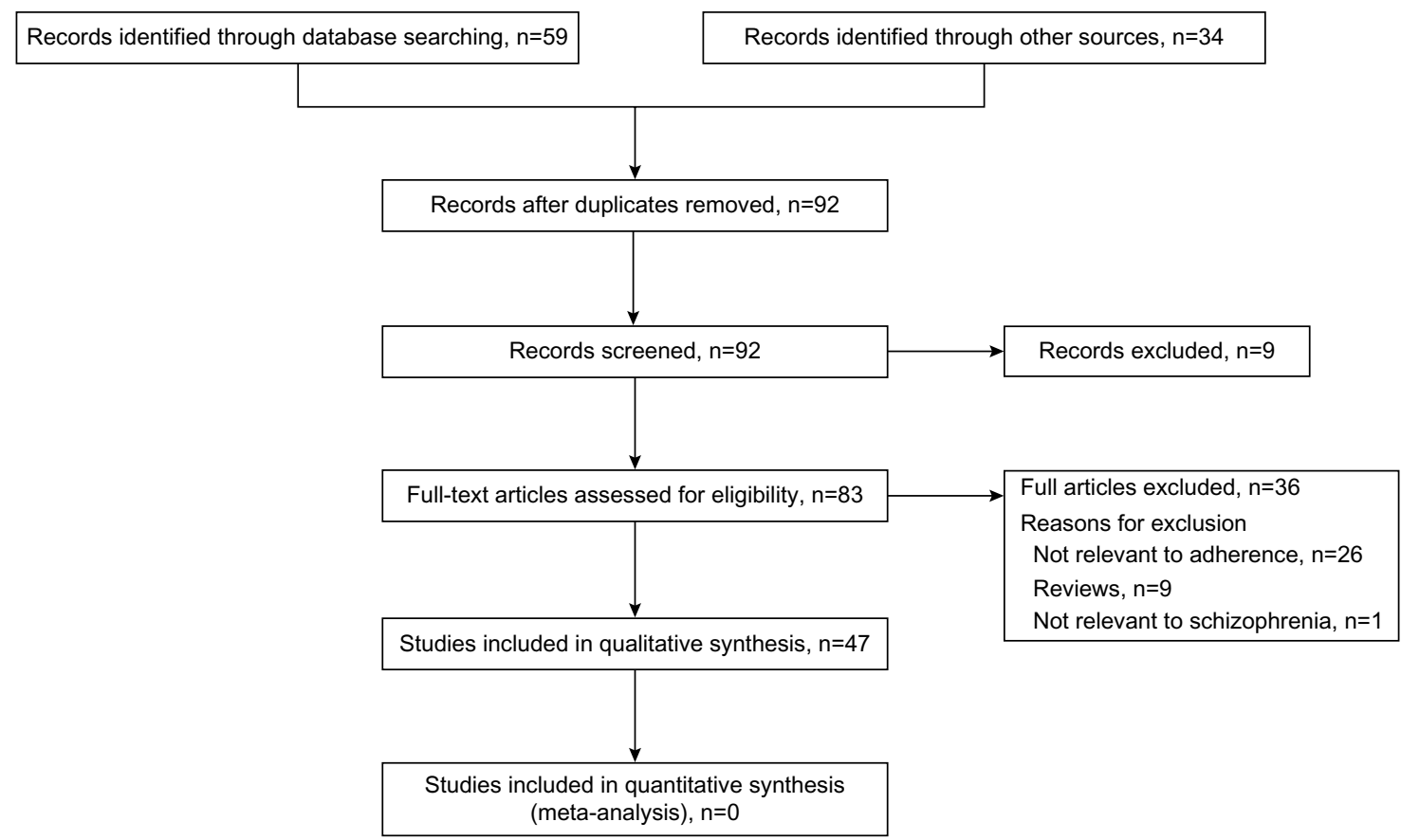

Figure I Flow diagram of the different phases of information retrieval.

\section{The burden of nonadherence in patients with schizophrenia}

Increased risk of relapse and hospitalization is the most important clinical consequence of patient nonadherence to prescribed schizophrenia medications. In a study of 1,646 patients with schizophrenia hospitalized after a relapse, nonadherence to antipsychotic medication was the most frequently cited reason for hospitalization $(58.6 \%) .{ }^{14}$ In a survey of 876 patients with schizophrenia, $57.5 \%$ reported incomplete adherence to treatment; patients with complete adherence were significantly less likely to be hospitalized or to visit an emergency room for a mental health reason. ${ }^{10}$ In a San Diego Medicaid population (2,801 person-years), nonadherent patients were approximately 2.5 -fold more likely to be hospitalized for psychiatric reasons versus adherent patients. ${ }^{15}$ In a study of 50 outpatients with schizophrenia who had previously been hospitalized, $52 \%$ had discontinued medication during their illness. ${ }^{11}$ Fifty-one percent of these patients were readmitted to the hospital during their illness; nonadherence to prescribed medication and substance abuse were noted as possible reasons for patient relapse.

In addition to the clinical consequences, nonadherence to antipsychotic medications prescribed for the treatment of schizophrenia accounts for a notable financial burden on the health care system. A 2008 study estimated that there were 121,838 inpatient days attributable to gaps in antipsychotic treatment among Medicaid recipients with schizophrenia, which corresponded to approximately $\$ 106$ million in costs. ${ }^{16}$ In a Florida Medicaid population of patients with schizophrenia $(n=10,330)$, there was a significant inverse correlation between adherence and health care costs. ${ }^{17}$ The total per-user-per-month costs were higher in patients with negligible adherence $(<25 \%)$ compared with patients with maximal adherence $(75 \%-100 \%)$ for all three medication classes that were evaluated (atypical antipsychotic monotherapy, $\$ 133$ higher; typical antipsychotic monotherapy, \$294 higher; atypical and typical antipsychotic combination therapy, \$221 higher). ${ }^{17}$ In a San Diego Medicaid population (2,801 person-years), hospital-related costs were significantly higher in nonadherent patients than in adherent patients, although total estimated costs were higher for adherent patients because of increased pharmacy-related expenses. ${ }^{15}$ In a UK survey of institutionalized patients receiving antipsychotic medication $(\mathrm{N}=658)$, nonadherence was associated with excess inpatient costs of approximately $£ 2,500$ per patient per year and excess total service costs of more than $£ 5,000$ per patient per year. ${ }^{18}$

\section{Factors influencing nonadherence}

Given the clinical and economic importance of adherence, it is important to identify and address factors associated with nonadherence to antipsychotic medication, from both the individual patient and societal perspectives. Four primary types of factors were identified: antipsychotic drug class, 
Table I Summary of references included in review

\begin{tabular}{|c|c|c|}
\hline Study & Study overview & Key findings \\
\hline $\begin{array}{l}\text { Aagaard and } \\
\text { Müller-Nielsen }{ }^{40}\end{array}$ & $\begin{array}{l}\text { - 2-year case-control study of ACT in } 174 \text { patients; } \\
\text { majority of patients diagnosed with schizophrenia } \\
\text { - Adherence not assessed as an outcome measure }\end{array}$ & $\begin{array}{l}\text { - ACT improved patient functioning and satisfaction with } \\
\text { treatment and reduced hospitalizations } \\
\text { - No improvement in positive or negative symptom control } \\
\text { at } 24 \text { months }\end{array}$ \\
\hline Becker et al ${ }^{17}$ & $\begin{array}{l}\text { 2-year retrospective intent-to-treat study using } \\
\text { Florida Medicaid claims data on 10,330 patients } \\
\text { with schizophrenia }\end{array}$ & - Adherence and health care costs were inversely correlated \\
\hline Boardman et $\mathrm{al}^{8}$ & $\begin{array}{l}\text { - Study of } 8 \mathrm{I} \text { patients with schizophrenia in Australia } \\
\text { - Assessment was with the Factors Influencing } \\
\text { Neuroleptic Medication Taking Scale }\end{array}$ & $\begin{array}{l}\text { - Most }(91 \%) \text { patients had case managers, including mental } \\
\text { health nurses, occupational therapists, psychologists, and } \\
\text { social workers; all had medical practitioners, and } 86 \% \text { had } \\
\text { a psychiatrist } \\
\text { - Case managers were the easiest providers to access; } \\
\text { psychiatrists were the hardest to access } \\
\text { - }>80 \% \text { of patients believed that their psychiatrist or case } \\
\text { manager had sufficient knowledge to treat them } \\
\text { - } 90 \% \text { were satisfied with their case manager or psychiatrist, } \\
\text { but } 16 \% \text { were dissatisfied with their general practitioner }\end{array}$ \\
\hline Chen et al ${ }^{46}$ & $\begin{array}{l}\text { 22-week, multicenter, randomized, open-label trial } \\
\text { in } 199 \text { patients with schizophrenia } \\
\text { - Reasons for treatment discontinuation were } \\
\text { assessed using the Reasons for Antipsychotic } \\
\text { Discontinuation/Continuation }\end{array}$ & $\begin{array}{l}\text { Persistence with antipsychotic medication was linked with } \\
\text { perception of benefits of continued treatment } \\
\text { - Discontinuation was linked with continued symptoms and } \\
\text { adverse events }\end{array}$ \\
\hline Cortesi et $\mathrm{al}^{3}$ & $\begin{array}{l}\text { - I-year, naturalistic, longitudinal, ambispective } \\
\text { (both retrospective and prospective) study of } \\
66 \mathrm{I} \text { patients with schizophrenia } \\
\text { - Outcomes included health-related quality of } \\
\text { life, demographic data, PANSS, Clinical Global } \\
\text { Impression - Severity of Illness, Global Assessment } \\
\text { of Functioning, compliance, and attitude toward } \\
\text { antipsychotic treatment }\end{array}$ & $\begin{array}{l}\text { - During follow-up, } 23 \% \text { of patients switched at least once } \\
\text { to a different drug class, switched to a combination, or } \\
\text { discontinued } \\
\text { - Atypical antipsychotics were associated with improved } \\
\text { persistence (adherence not reported) compared with } \\
\text { typical antipsychotics } \\
\text { - Initiating antipsychotic treatment was associated with } \\
\text { improvements in symptoms, function, and health-related } \\
\text { quality of life }\end{array}$ \\
\hline Diaz et al ${ }^{47}$ & $\begin{array}{l}\text { - Prospective study of } 50 \text { patients with schizophrenia } \\
\text { - Adherence with two atypical antipsychotics and } \\
\text { with typical antipsychotics was compared }\end{array}$ & $\begin{array}{l}\text { - Adherence with an atypical antipsychotic was superior } \\
\text { to that with a typical agent } \\
\text { - Secondary analyses revealed that adherence was better } \\
\text { with the first atypical agent because of less-frequent dosing } \\
\text { rather than because of a difference between drug classes }\end{array}$ \\
\hline $\begin{array}{l}\text { DiBonaventura } \\
\text { et al }\end{array}$ & $\begin{array}{l}\text { - Analysis of data from a cross-sectional nationwide } \\
\text { survey of } 876 \text { patients with schizophrenia on } \\
\text { antipsychotic medication } \\
\text { - The impact of adverse events on adherence was } \\
\text { assessed }\end{array}$ & $\begin{array}{l}\text { - Nonadherence was associated with symptom relapse and } \\
\text { increased hospitalizations }\end{array}$ \\
\hline Dolder et $\mathrm{a}^{21}$ & $\begin{array}{l}\text { - Analysis of claims data on } 288 \text { patients with } \\
\text { schizophrenia treated in the US Veterans Affairs } \\
\text { Healthcare System }\end{array}$ & $\begin{array}{l}\text { - Adherence to an atypical antipsychotic was significantly } \\
\text { higher than with a typical antipsychotic at } 6 \text { months but } \\
\text { not at } 12 \text { months }\end{array}$ \\
\hline Farabee et $\mathrm{al}^{5}$ & $\begin{array}{l}\text { - Study using interview data on I50 parolees with } \\
\text { schizophrenia in the California Department of } \\
\text { Corrections }\end{array}$ & $\begin{array}{l}\text { Patients with schizophrenia were four-fold more likely to } \\
\text { be adherent if they were prescribed an atypical agent and } \\
\text { two-fold more likely if they had a guardian } \\
\text { - Patients were ten-fold more likely to be adherent if they } \\
\text { were prescribed an atypical agent and had a guardian }\end{array}$ \\
\hline $\begin{array}{l}\text { Gianfrancesco } \\
\text { et al }{ }^{19}\end{array}$ & $\begin{array}{l}\text { - Analysis of pharmacy claims data on 5,683 patients } \\
\text { with schizophrenia }\end{array}$ & $\begin{array}{l}\text { - Treatment with an atypical antipsychotic was associated with } \\
\text { greater adherence during treatment compared with a typical } \\
\text { agent } \\
\text { - There was no significant difference in treatment persistence }\end{array}$ \\
\hline Gilmer et al ${ }^{15}$ & $\begin{array}{l}\text { - Analysis of claims data on } 1,619 \text { patients with } \\
\text { schizophrenia }\end{array}$ & $\begin{array}{l}\text { Nonadherent patients were approximately } 2.5 \text {-fold more } \\
\text { likely to be hospitalized for psychiatric reasons than } \\
\text { adherent patients }\end{array}$ \\
\hline
\end{tabular}


Table I (Continued)

\begin{tabular}{|c|c|c|}
\hline Study & Study overview & Key findings \\
\hline Granholm et $\mathrm{al}^{43}$ & $\begin{array}{l}\text { - Retrospective chart review of } 50 \text { consecutive } \\
\text { patients with a substance-abuse disorder and either } \\
\text { schizophrenia, depressive disorder, or bipolar disorder } \\
\text { - Patients were treated by an ACT team }\end{array}$ & $\begin{array}{l}\text { - ACT treatment had a positive effect on hospitalizations } \\
\text { - Adherence was not assessed as an outcome measure }\end{array}$ \\
\hline Hudson et $\mathrm{al}^{2}$ & $\begin{array}{l}\text { - Analysis of data on } 399 \text { patients with } \\
\text { schizophrenia who participated in the } \\
\text { Schizophrenia Guidelines Project; complete } \\
\text { data were available from } 153 \text { patients }\end{array}$ & $\begin{array}{l}\text { - Adverse events were cited more frequently than efficacy } \\
\text { as a reason for nonadherence } \\
\text { - Stigma was the most frequently described barrier to } \\
\text { adherence }\end{array}$ \\
\hline Hudson et $\mathrm{al}^{45}$ & $\begin{array}{l}\text { - Analysis of } 349 \text { patients with schizophrenia who } \\
\text { received a nurse-facilitated enhanced-treatment } \\
\text { strategy designed to address barriers to adherence } \\
\text { or usual care } \\
\text { - Nurses interviewed patients, completed a checklist } \\
\text { of nine potential barriers to adherence, and } \\
\text { worked with patients to develop strategies } \\
\text { to improve adherence }\end{array}$ & $\begin{array}{l}\text { - At } 6 \text { months, patients receiving the enhanced-treatment } \\
\text { strategy were nearly twice as likely to be adherent with } \\
\text { therapy as those receiving usual care } \\
\text { - Patients who were adherent at follow-up had significantly } \\
\text { better PANSS scores compared with nonadherent patients }\end{array}$ \\
\hline Karow et $\mathrm{al}^{41}$ & $\begin{array}{l}\text { - 24-month comparison of ACT and standard care } \\
\text { in } 120 \text { patients with psychosis } \\
\text { - Assessments included PANSS, quality-of-life measures, } \\
\text { service use, and treatment costs }\end{array}$ & $\begin{array}{l}\text { - ACT interventions improved patient outcomes at costs } \\
\text { similar to usual care } \\
\text { - Superior cost-effectiveness of ACT can only be achieved } \\
\text { by preventing hospitalization because outpatient care is } \\
\text { more expensive }\end{array}$ \\
\hline Kim et $\mathrm{al}^{30}$ & $\begin{array}{l}\text { - A cross-sectional survey of } 351 \text { patients with } \\
\text { schizophrenia }\end{array}$ & - Copayment burden was inversely correlated with adherence \\
\hline Kirson et $\mathrm{al}^{27}$ & $\begin{array}{l}\text { - Meta-analysis of LAls versus oral antipsychotics in } \\
\text { patients with schizophrenia }\end{array}$ & $\begin{array}{l}\text { LAls are superior to oral agents in observational studies } \\
\text { but not in randomized controlled trials } \\
\text { - Adherence to prescribed medication is more tightly } \\
\text { controlled in a randomized controlled trial, improving } \\
\text { outcomes compared with a real-world setting }\end{array}$ \\
\hline Knapp et al $^{18}$ & $\begin{array}{l}\text { - National survey data of psychiatric morbidity in the } \\
\text { UK among patients prescribed antipsychotic } \\
\text { medication } \\
\text { - Treatment costs in adherent and nonadherent } \\
\text { patients were compared }\end{array}$ & $\begin{array}{l}\text { - Nonadherence was associated with excess inpatient costs } \\
\text { of approximately } £ 2,500 / \text { patient/year and excess total } \\
\text { service costs of more than } £ 5,000 / \text { patient/year }\end{array}$ \\
\hline Kotzè et al' & $\begin{array}{l}\text { - Naturalistic observational study of } 50 \text { patients with } \\
\text { schizophrenia } \\
\text { - Relapse rates and hospitalizations were compared } \\
\text { in adherent and nonadherent patients }\end{array}$ & $\begin{array}{l}\text { - Nonadherence with treatment was associated with symptom } \\
\text { relapse and increased hospitalizations }\end{array}$ \\
\hline $\begin{array}{l}\text { Kozuki and } \\
\text { Schepp }\end{array}$ & $\begin{array}{l}\text { - Descriptive study of } 106 \text { patients with psychosis } \\
\text { - Outcomes included the Ratings of Medications } \\
\text { Influences Scale and the PANSS }\end{array}$ & $\begin{array}{l}\text { - Symptoms measured using the PANSS were the strongest } \\
\text { predictor of adherence or nonadherence } \\
\text { - Other factors promoting nonadherence included poverty/ } \\
\text { unemployment and opposition from family members }\end{array}$ \\
\hline Lang et $\mathrm{al}^{9}$ & $\begin{array}{l}\text { - Analysis of claims data on } 12,032 \text { patients who } \\
\text { received } \geq 1 \text { antipsychotic prescription before } \\
\text { enrollment and } \geq 1 \text { during follow-up } \\
\text { - Study measures included adherence, persistence, } \\
\text { medication consistency, maximum continuous gap } \\
\text { in treatment, and hospitalization }\end{array}$ & $\begin{array}{l}\text { - Predictors of nonadherence included newly starting treatment; } \\
\text { younger age; substance abuse; and use of a mood stabilizer, } \\
\text { antidepressant, anxiolytic, or anticholinergic medication } \\
\text { - Prescribing an LAI or both typical and atypical antipsychotics } \\
\text { was associated with a low risk of nonadherence } \\
\text { - Predictors of hospitalization included diagnosis of substance } \\
\text { abuse or another psychosis and nonadherence with therapy }\end{array}$ \\
\hline Leucht et $\mathrm{al}^{26}$ & $\begin{array}{l}\text { - A systematic review and meta-analysis comparing } \\
\text { depot and oral antipsychotics } \\
\text { - Outcomes included relapse rates, rehospitalizations } \\
\text { due to psychopathology, and nonadherence }\end{array}$ & $\begin{array}{l}\text { - Fewer patients treated with LAI formulations experienced } \\
\text { relapse or were nonadherent } \\
\text { - There was no significant difference in rehospitalization rates }\end{array}$ \\
\hline Manuel et $\mathrm{al}^{38}$ & $\begin{array}{l}\text { - Study evaluating } 198 \text { patients with concomitant } \\
\text { psychotic and substance abuse issues to determine } \\
\text { whether enrollment in ACT or standard clinical } \\
\text { case management affect treatment adherence }\end{array}$ & $\begin{array}{l}\text { Patients enrolled in ACT had significantly greater adherence } \\
\text { to treatment than those enrolled in standard clinical case } \\
\text { management }\end{array}$ \\
\hline
\end{tabular}

(Continued) 
Table I (Continued)

\begin{tabular}{|c|c|c|}
\hline Study & Study overview & Key findings \\
\hline $\begin{array}{l}\text { Marcus and } \\
\text { Olfson }^{16}\end{array}$ & $\begin{array}{l}\text { - Multivariate regression analyses of California } \\
\text { Medicaid data to estimate the percentage of hospital } \\
\text { admissions and days in hospital that are due to } \\
\text { nonadherence to an antipsychotic in patients with } \\
\text { schizophrenia } \\
\text { - This fraction was then applied to national estimates } \\
\text { of total admissions and costs due to hospitalizations }\end{array}$ & $\begin{array}{l}\text { - } 36.6 \% \text { of acute inpatient admissions occurred during } \\
\text { medication gaps } \\
\text { - Nationally, approximately } 122,000 \text { inpatient days and } \\
\$ 106 \text { million in costs were attributable to gaps in treatment }\end{array}$ \\
\hline McCann et $\mathrm{al}^{48}$ & $\begin{array}{l}\text { - Study of } 8 \mathrm{I} \text { patients with schizophrenia to determine } \\
\text { whether there were differences in the factors } \\
\text { influencing adherence between patients in a rural } \\
\text { versus an urban setting } \\
\text { - Outcome measure was the Factors Influencing } \\
\text { Neuroleptic Medication Taking Scale }\end{array}$ & $\begin{array}{l}\text { - Rural patients were more likely to live alone, be involved } \\
\text { in religious activities, and indicate that adverse events } \\
\text { decreased the likelihood of their taking medication } \\
\text { - Patients in an urban setting were more likely to feel they } \\
\text { had a good relationship with their case manager and have } \\
\text { access to health professionals } \\
\text { - There was no significant association between any of these } \\
\text { differences and corresponding differences in medication } \\
\text { adherence }\end{array}$ \\
\hline McCann et $\mathrm{al}^{49}$ & $\begin{array}{l}\text { - Study of } 81 \text { patients with schizophrenia to evaluate } \\
\text { the association between side effects and adherence } \\
\text { - Outcome measure was the Liverpool University } \\
\text { Neuroleptic Side Effect Rating Scale }\end{array}$ & $\begin{array}{l}\text { - Accumulated side effects were not associated with } \\
\text { medication omission in either men or women } \\
\text { - Medication omission was not associated with any of the } \\
\text { seven subscales of the Liverpool University Neuroleptic } \\
\text { Side Effect Rating Scale }\end{array}$ \\
\hline $\begin{array}{l}\text { McCann and } \\
\mathrm{Lu}^{34}\end{array}$ & $\begin{array}{l}\text { - Study of } 8 \mathrm{I} \text { patients with schizophrenia to determine } \\
\text { whether support from significant others improves } \\
\text { adherence } \\
\text { - Outcome measure was the Factors Influencing }\end{array}$ & $\begin{array}{l}\text { - There was no significant difference in self-reported } \\
\text { adherence between patients with support from significant } \\
\text { others and those without such support }\end{array}$ \\
\hline
\end{tabular}

McHugo et $\mathrm{al}^{42}$

Neuroleptic Medication Taking Scale

- Comparison of parallel (community-based) and integrated (dedicated) housing services in 121 adults with serious mental illness $(72.7 \%$ with a schizophrenia spectrum disorder) who were homeless or at risk of homelessness

Menzin et $\mathrm{al}^{20} \quad$ - Analysis of medical and pharmacy claims for California Medicaid patients with schizophrenia comparing atypical and typical antipsychotic medications

- Outcomes included treatment discontinuation and switching, persistence with therapy, and concomitant medications

Offord et $\mathrm{al}^{25}$

- Retrospective analysis of Medicare-insured patients with schizophrenia who were prescribed an LAI or oral antipsychotic

- Outcomes included adherence, hospitalizations, and length of hospital stay

Olfson et $\mathrm{al}^{29}$

- Survey of psychiatrists treating 300 patients with schizophrenia to assess the effects of patient awareness of illness on clinical presentation, management, and course of disease

- Patients had been under their care for $\geq \mathrm{I}$ year and had shown nonadherence at some point

- Integrated housing was associated with more days of stable housing, greater life satisfaction, and greater reductions in psychiatric symptoms

- Patients on atypical medications were significantly less likely to discontinue an atypical antipsychotic initiated in the previous 3 months or to switch medications

- Patients on atypical medications were less likely to use concomitant antidepressants and mood stabilizers, but the difference was not significant

- Most (84\%) patients with schizophrenia did not receive an LAI

- Patients on LAls had better medication adherence compared with those on oral agents

- Patients initiating LAls experienced significantly fewer all-cause and schizophrenia-related hospitalizations and had significantly shorter hospital stays compared with those initiating an oral antipsychotic during a 12-month follow-up period

- In patients without awareness, the leading causes of nonadherence were denial of illness (72\%), adverse events (6\%), motivational deficit (4\%), and lack of family support for taking the medication (3\%)

- In patients with awareness, the leading causes were denial of illness (18\%), paranoia and substance abuse (I $2 \%$ each), motivational deficit (8\%), patient perception of treatment response and cognitive disorientation ( $7 \%$ each), cost of the medication (6\%), and stigma and lack of family support for taking the medication ( $4 \%$ each)

(Continued) 
Table I (Continued)

\begin{tabular}{|c|c|c|}
\hline Study & Study overview & Key findings \\
\hline Peng et $\mathrm{al}^{6}$ & $\begin{array}{l}\text { - I2-month mirror-image study of claims data for } \\
\text { I47 patients with schizophrenia who were switched } \\
\text { from an oral to an LAI antipsychotic } \\
\text { - Outcome measures included medication-possession } \\
\text { ratio, hospitalizations, and direct treatment costs }\end{array}$ & $\begin{array}{l}\text { - Switching to an LAI increased medication-possession } \\
\text { ratios from } 36.8 \% \text { to } 60.3 \% \text { over } 6 \text { months compared } \\
\text { with the } 6 \text { months before the switch } \\
\text { - The proportion of patients with hospitalizations } \\
\text { decreased from } 49.7 \% \text { to } 22.4 \% \\
\text { - Mean direct treatment costs decreased significantly } \\
\text { from } \$ \text { II, III to } \$ 7,884\end{array}$ \\
\hline Petersen et $\mathrm{al}^{39}$ & $\begin{array}{l}\text { - Randomized controlled trial comparing an integrated } \\
\text { treatment approach to standard treatment in } \\
547 \text { patients with first-episode schizophrenia } \\
\text { - The integrated intervention consisted of ACT } \\
\text { enhanced by greater family involvement and } \\
\text { social skills training } \\
\text { - Outcomes included treatment adherence and } \\
\text { positive and negative symptom scores }\end{array}$ & $\begin{array}{l}\text { - During I year of treatment, patients receiving } \\
\text { integrated treatment were significantly less likely to } \\
\text { discontinue treatment than those receiving standard } \\
\text { care ( } 8 \% \text { versus } 22 \%) \\
\text { - Positive and negative symptoms were both significantly } \\
\text { better with the integrated treatment compared with } \\
\text { standard care }\end{array}$ \\
\hline Purvis et $\mathrm{al}^{28}$ & $\begin{array}{l}\text { - 3-month retrospective study of } 53 \text { patients with } \\
\text { schizophrenia initiating risperidone } \mathrm{LAl} \text { and then } \\
\text { transitioning from an inpatient state hospital to an } \\
\text { outpatient community mental health center }\end{array}$ & $\begin{array}{l}\text { - Only } 24 \% \text { of patients received all six scheduled } \\
\text { bimonthly injections } \\
\text { - } 59 \% \text { of patients who initiated treatment as inpatients } \\
\text { did not receive a single injection following discharge }\end{array}$ \\
\hline $\begin{array}{l}\text { Rabinovitch } \\
\text { et } \mathrm{al}^{7}\end{array}$ & $\begin{array}{l}\text { - Study of } 100 \text { consecutive patients with schizophrenia } \\
\text { - Outcomes included adherence, patient demographic } \\
\text { and clinical characteristics, and level of social support }\end{array}$ & $\begin{array}{l}\text { - } 56 \text { patients }(54.9 \%) \text { were deemed adherent with } \\
\text { treatment ( } \geq 76 \% \text { of doses) } \\
\text { - Nonadherent patients were less likely to have received } \\
\text { good social support and were more likely to be single }\end{array}$ \\
\hline $\begin{array}{l}\text { Rabinovitch } \\
\text { et } \mathrm{al}^{33}\end{array}$ & $\begin{array}{l}\text { - 6-month study of } 81 \text { patients with first-episode } \\
\text { schizophrenia } \\
\text { - Outcomes included adherence and } \\
\text { Multidimensional Scale of Perceived Social Support }\end{array}$ & $\begin{array}{l}\text { - Medication adherence was positively correlated with } \\
\text { level of social support at baseline and months I, 2, and } 4\end{array}$ \\
\hline $\begin{array}{l}\text { Rummel-Kluge } \\
\text { et al' }\end{array}$ & $\begin{array}{l}\text { - A survey of } 699 \text { psychiatrists treating } 5,729 \text { patients } \\
\text { with schizophrenia } \\
\text { - Psychiatrists rated patient adherence and factors } \\
\text { associated with nonadherence }\end{array}$ & $\begin{array}{l}\text { - } 68 \% \text { of patients were rated as having partial compliance } \\
\text { of insight into disease ( } 66 \%) \text {, denial of disease }(63 \%) \text {, } \\
\text { embarrassment at taking medication }(62 \%) \text {, and living } \\
\text { conditions not suitable for compliance }(46 \%) \\
\text { - } 62 \% \text { needed someone to remind them to take their } \\
\text { medication, } 55 \% \text { had cognitive problems, and } 34 \% \text { were } \\
\text { believed to have substance-abuse issues }\end{array}$ \\
\hline San et $\mathrm{al}^{14}$ & $\begin{array}{l}\text { - An epidemiologic, multicenter, noninterventional } \\
\text { study to identify sociodemographic, clinical, and } \\
\text { treatment characteristics associated with relapse } \\
\text { in schizophrenia } \\
\text { - Data were collected from } 29 \mathrm{I} \text { psychiatrists treating } \\
\text { a total of I,646 patients for the } 3 \text { years before study } \\
\text { enrollment and during } 12 \text { months of follow-up }\end{array}$ & $\begin{array}{l}\text { - The leading cause of hospitalization for relapse was } \\
\text { nonadherence ( } 58.6 \%) \\
\text { - Adherence with treatment during the } 3 \text { years before } \\
\text { admission was highest in patients treated with LAI } \\
\text { atypical antipsychotics ( } 41.9 \%) \text {, followed by LAI typical } \\
\text { antipsychotics ( } 34.7 \%) \text {, oral atypical antipsychotics } \\
\text { ( } 25.8 \%) \text {, and oral typical antipsychotics ( } 22.4 \%) \\
\text { - Prescribing of LAls and atypical agents increased } \\
\text { following discharge, but } 38.6 \% \text { of patients relapsed } \\
\text { during the } 12 \text { months after hospital discharge, with } \\
\text { no difference according to drug class or formulation }\end{array}$ \\
\hline
\end{tabular}


Table I (Continued)

\begin{tabular}{|c|c|}
\hline Study & Study overview \\
\hline Stroup et $\mathrm{al}^{50}$ & $\begin{array}{l}\text { - Summary of the revised Schizophrenia Patient } \\
\text { Outcomes Research Team recommendations for } \\
\text { the management of patients with schizophrenia }\end{array}$ \\
\hline
\end{tabular}

Valenstein et $\mathrm{al}^{37}$

Velligan et $\mathrm{a}^{22}$

Weiss et $\mathrm{al}^{36}$

West et $\mathrm{al}^{23}$

Wilk et $\mathrm{al}^{35}$

Zeber et $\mathrm{al}^{32}$

Zhu et $\mathrm{al}^{24}$
- Analysis of 3-year data from a prospective, nonrandomized, noninterventional, multisite study of 299 patients with schizophrenia

- Time to all-cause discontinuation was compared in patients prescribed an oral typical antipsychotic versus those prescribed depot formulations of the same agents

- Analysis of 24-month adherence in 763 patients with schizophrenia treated using an ACT approach

- The primary outcome was medication-possession ratio

- Survey data were collected from an expert panel ( $n=4$ I completed the survey) on addressing adherence problems in patients with persistent mental illness using a 9-point scale

- Cross-sectional, longitudinal, prospective study of 162 patients with schizophrenia

- Variables related to nonadherence were explored using Spearman and Kendall correlation coefficients

- Cox regression analyses were conducted to identify factors associated with adherence

- Survey of 534 psychiatrists about treating patients with schizophrenia who were nonadherent with an oral antipsychotic in the previous year

- Psychiatrists reported on their use of depot antipsychotics

- Multiple regression analyses were performed to assess associations between individual variables and depot antipsychotic prescribing

- A survey of psychiatrists treating a total of 310 patients stratified according to level of family contact

- Multiple logistic regression analyses were performed to examine differences in adherence between patients with high and low levels of family contact

- Analyses of data from the National Psychosis Registry for patients with schizophrenia treated through the US Department of Veterans Affairs

- Longitudinal mixed models were used to compare adherence in patients subject to copays $(n=40,654)$ and those not subject to copays $(n=39,983)$

Abbreviations: ACT, assertive community treatment; LAI, long-acting injectable; MHDO, mental health development officers; PANSS, Positive and Negative Syndrome Scale.

\section{Key findings}

- Although there is no definitive evidence that atypical antipsychotics are superior to typical agents in acute efficacy, it is hoped that improved tolerability will improve adherence and justify their higher costs

- The guidelines strongly advocate use of LAls in patients at risk of nonadherence but acknowledge that it may be difficult to transition stabilized patients to a regimen they find painful or inconvenient

- Patients receiving ACT were more than twice as likely as those receiving usual care to have $>80 \%$ adherence

- Depending on the time point, adherence in the ACT group was $73 \%-81 \%$, compared with $54 \%-60 \%$ with non-ACT treatment

- Decreasing dose frequency may improve adherence, but patient preference may be a more important determinant of adherence

- There is little conclusive evidence that atypical antipsychotics improve adherence compared with typical agents

- Difficulties with adherence were significantly associated with low Global Assessment of Functioning Scale score, substance use, and a weaker working alliance with a therapist

- Factors associated with good adherence were a good working alliance with a physician, higher global functioning, and use of the atypical antipsychotic clozapine

- Only $17.6 \%$ of patients were started on a depot antipsychotic

- Depot antipsychotic prescribing was related to living in a mental health residence, recent homelessness, having public insurance, recent inpatient admission attributed to nonadherence, longer duration of nonadherence, and average to above-average intelligence

- Depot prescribing was negatively associated with use of atypical antipsychotics and use of other psychotropic medications

- Patients with high and low levels of family contact did not differ with respect to duration of nonadherence or the frequency of treatment discontinuations or hospitalizations due to nonadherence

- Patients with extensive family contact were, however, more likely to change medication in response to nonadherence

- Psychiatrists treating patients with extensive family contact were more likely to use psychological, behavioral, and family-oriented interventions to improve outcomes

- Prescriptions, total and medical fills, were similar between groups

- However, after an $8 \%$ increase in copays, utilization growth slowed significantly in the copay group compared with the noncopay group

- The copay group was $5 \%$ more likely to have a hospitalization after the increase

- Mean ( \pm standard deviation) time to treatment discontinuation of a depot formulation antipsychotic was significantly longer than with an oral formulation $(292 \pm 106$ days versus $270 \pm 108$ days, $P<0.01$ )

- Patients receiving a depot formulation were twice as likely to continue treatment (hazard ratio $1.94,95 \%$ confidence interval I.3-2.9; $P<0.00$ I) 
antipsychotic drug formulation, patient-specific factors, and family and social support system.

\section{Antipsychotic drug class}

Some evidence suggests that patients with schizophrenia may be more adherent to atypical antipsychotics than to typical antipsychotics, but the data are inconclusive. In a retrospective claims database analysis $(\mathrm{N}=5,683)$, the use of any of four atypical antipsychotics included in the study was associated with significantly higher patient-adjusted medication-possession ratios compared with the use of typical antipsychotics $(P \leq 0.049) .{ }^{19}$ However, there was no significant difference between typical and atypical antipsychotics with respect to treatment duration. ${ }^{19}$ In a study of 150 parolees on antipsychotic medication, patients prescribed an atypical antipsychotic were four times more likely to be adherent than those prescribed a typical antipsychotic. ${ }^{5}$ In a Florida Medicaid population ( $\mathrm{N}=10,330)$, the proportion of patients with maximal adherence $(75 \%-100 \%)$ was higher in those receiving an atypical antipsychotic (71.7\%) compared with those receiving a typical antipsychotic (55.8\%). ${ }^{17}$ In a study of California Medicaid patients ( $n=298)$, fewer patients receiving atypical antipsychotics discontinued treatment during 1 year of follow-up (33\%) or switched treatment (18\%) than did those receiving typical antipsychotics (58\% and $33 \%$, respectively; $P<0.05) .{ }^{20}$ However, the percentage of days covered with prescribed medication was similar between groups, with both groups possessing their medication for a similar percentage of days (atypical versus typical: 61\% versus $58 \%$ ).

In a naturalistic, longitudinal study of 637 patients with schizophrenia, atypical antipsychotics were associated with improved persistence compared with typical antipsychotics during 1 year of follow-up (402.8 versus 263.0 patient-days), but direct measures of adherence were not made in this study. ${ }^{3}$ In a study of 341 patients with schizophrenia, adherence was better with atypical than with typical antipsychotics in the short term, but the advantage was not durable. ${ }^{21}$ Patients receiving atypical antipsychotics had a significantly higher compliant fill rate at 6 months $(57.4 \%$ versus $49.9 \%, P=0.05)$, but the difference favoring atypical agents was not significant at 12 months $(54.9 \%$ versus $50.1 \%, P=0.11) .{ }^{21}$

Velligan et al reported the findings of an expert consensus panel convened to evaluate factors affecting treatment adherence and develop recommendations for assessing and addressing adherence problems in patients with serious and persistent mental illness. ${ }^{22}$ Using a 9-point scale, experts who completed the survey $(n=41)$ rated persistent adverse events as one of the two most important contributors to nonadherence (lack of disease awareness was the other); lack of efficacy and continued symptoms were rated as only slightly less important. While emphasizing the importance of tolerability, the panel also reported that there had been few conclusive data to suggest that atypical antipsychotics had improved treatment adherence by offering improved tolerability versus typical antipsychotics. ${ }^{22}$

\section{Antipsychotic drug formulation}

Although patients often prefer oral medications over injectable medications, some benefits can be garnered from the use of LAI medications in appropriate patients. LAI antipsychotic formulations require only once- or twice-monthly injections from a physician, compared with daily self-administered doses associated with oral formulations. This less-frequent dosing may improve adherence in some patients and correlate with improved patient outcomes.

Initiation of an LAI prescription has been associated with previous inpatient psychiatric admission due to medication nonadherence. ${ }^{23}$ In a 3-year, noninterventional, prospective study of 299 patients with schizophrenia, mean ( \pm standard deviation) time to discontinuation of an LAI was significantly longer than the time to discontinuation with an oral formulation ( $292 \pm 106$ days versus $270 \pm 108$ days, $P<0.01$ ), and patients receiving an LAI were twice as likely to continue treatment (hazard ratio 1.94, 95\% confidence interval [CI] $1.3-2.9 ; P<0.001) .{ }^{24}$ In a 12 -month mirror-image study, switching patients $(\mathrm{N}=147)$ from an oral antipsychotic to an LAI formulation improved medication-possession ratios (from $36.8 \%$ to $60.3 \%$ ), decreased the proportion of patients with psychiatric hospitalizations (from $49.7 \%$ to $22.4 \%$ ), and reduced mean direct costs (from $\$ 11,111$ to $\$ 7,884$ ) during the 6 months after versus the 6 months before switching. ${ }^{6}$ In a retrospective database analysis of patients with schizophrenia $(\mathrm{N}=3,004$ commercially insured, $\mathrm{n}=665$ insured by Medicare), those initiating LAIs had significantly higher medication-possession ratios compared with those on oral antipsychotics (commercially insured, 0.67 versus 0.56 , respectively $[P<0.001]$; Medicare, 0.68 versus 0.59 , respectively $[P=0.005])$. Patients initiating LAIs also experienced significantly fewer all-cause and schizophrenia-related hospitalizations and had significantly shorter hospital stays than those initiating an oral antipsychotic during a 12-month follow-up period. ${ }^{25}$

Randomized controlled trial (RCT) data generally do not support the notion that LAIs confer improved adherence when compared with oral antipsychotics. In a meta-analysis 
of five clinical trials comparing LAIs with oral antipsychotics, LAIs provided a numeric but nonsignificant advantage in reducing the relative risk of nonadherence (risk ratio [RR] $0.75,95 \%$ CI $0.37-1.56) .{ }^{26}$ In a subsequent meta-analysis, LAIs were significantly superior to oral agents in prospective (four studies; RR 0.62, 95\% CI 0.48-0.81) and retrospective (four studies; RR 0.56, 95\% CI 0.44-0.71) observational studies, but no significant difference was observed between LAIs and oral agents in RCTs (four studies; RR 0.89, 95\% CI 0.64-1.22). ${ }^{27}$ One explanation for this observed difference in results between RCTs and observational studies is that adherence to prescribed medication is more tightly monitored in RCTs, with noncompliant patients often being discontinued before the end of the treatment period. Therefore, ascertaining true differences in adherence between LAIs and oral antipsychotic medications from RCTs poses challenges that may not be present in observational studies. ${ }^{27}$

Nonetheless, it remains unclear to what extent improved adherence in a real-world setting might improve clinical outcomes. Although LAIs can help some patients improve adherence to treatment, there is still potential for missed doses in an outpatient setting. In a 3-month retrospective study of patients with schizophrenia transitioning from an inpatient hospital setting to an outpatient community mental health center who were prescribed risperidone LAI, only $24 \%$ were fully compliant with treatment (ie, received all six of the scheduled risperidone LAI injections). ${ }^{28}$ Twenty-one of 53 patients $(40 \%)$ did not receive a single injection following discharge. Regression model analyses indicated that neither an aftercare appointment planned before discharge nor the presence of a case manager/guardian significantly improved patient adherence.

In addition to drug class and formulation, patient preference with regard to dosing frequency may affect adherence to treatment. ${ }^{22}$ Clinicians should therefore remain flexible when selecting an antipsychotic therapy. Consideration should be given to drug class, formulation, and dosing frequency, while also factoring in individual patient preference and likelihood of adherence to selected treatment.

\section{Patient-specific factors}

A variety of patient-specific factors that extend beyond medication effects contribute to patient adherence. In a study of 153 patients treated at US Veterans Affairs Medical Centers, the most common patient-reported barriers to adherence were stigma related to taking medications, adverse drug reactions, forgetting to take medications, and a lack of social support. ${ }^{2}$ In a survey of 699 psychiatrists treating 5,729 patients with schizophrenia, factors associated with partial adherence included a lack of insight into the need for medication (68\%), denial of illness $(63 \%-66 \%)$, embarrassment about taking medication every day (ie, stigma $-62 \%$ ), and living conditions unsuitable for adherence (46\%). ${ }^{1}$ Cognitive problems were reported in $55 \%$ of patients, and substance-abuse issues were believed to be present in $34 \%$ of patients. Another factor potentially affecting adherence was the fact that $62 \%$ of patients in this study required assistance from others to remind them to take their medication. ${ }^{1}$

Some patients exhibit a lack of awareness about their illness (anosognosia), which highlights the importance of the need for a personalized approach while implementing strategies to optimize adherence and support patients with schizophrenia. In a study of 300 patients with schizophrenia who had been nonadherent at some point during treatment, $203(68 \%)$ were considered to have awareness of their disease, and 97 (32\%) did not. ${ }^{29}$ Patients with awareness of their disease had periods of nonadherence that were significantly shorter, and they were significantly less likely to discontinue treatment compared with patients lacking disease awareness. The effectiveness (psychiatrist-rated) of several psychological-, behavioral-, or family-related interventions to address nonadherence was better in patients who were aware of their illness compared with those who were unaware. ${ }^{29}$ It should be noted, however, that in this study, patients with awareness of their illness were also more likely to have other characteristics that may contribute to nonadherence, including substance abuse and sensitivity to the stigma associated with taking antipsychotic medication. ${ }^{29}$ In the aforementioned study that surveyed 699 psychiatrists, ${ }^{2}$ stigma was the barrier to adherence most frequently described by patients, and research has shown that substance abusers are at a significantly higher risk for medication nonadherence compared with nonusers. ${ }^{9}$ A team approach to support adherence and overcome barriers to nonadherence is therefore essential in all patients, although the type and intensity of the intervention may vary based on the characteristics of the individual patient.

Several other factors have been identified that may adversely affect patient adherence to antipsychotic medication regimens. Patient access to health care services (affected by geographic location, transportation difficulties, and cultural or language issues) may influence patient adherence to antipsychotic therapy. ${ }^{8}$ Patients with schizophrenia are frequently unemployed and/or in poverty, ${ }^{30,31}$ which may contribute to nonadherence caused by the financial burden of medication (eg, medication copayments). ${ }^{30,32}$ Even small 
increases in insurance copayments have been associated with declining adherence and corresponding increases in psychiatric hospital admissions. ${ }^{32}$ Access to LAI antipsychotics has been shown to be influenced by patient insurance status. ${ }^{23}$ In this study, patients were more likely to be prescribed LAIs if they were part of a public insurance plan than if they had private insurance. ${ }^{23}$

\section{Family and social support system}

There are conflicting data concerning the effectiveness of family or other social support systems in improving adherence to antipsychotic medication in patients with schizophrenia. In a study of recent parolees with schizophrenia, adherence was greater in patients with a guardian. ${ }^{5}$ In a study of 100 patients admitted to a specialized early intervention service for treatment of first-episode psychosis, an "infrequent/moderate" social support rating from a case manager was significantly associated with nonadherence compared with a rating of "good support."7

In a 6-month Canadian study of 81 patients with first-episode schizophrenia, social support was positively associated with medication adherence at baseline and months 1, 2, and 4 of treatment but not at 5 or 6 months. ${ }^{33}$ An Australian study of patients with schizophrenia recruited by community-based case managers $(\mathrm{N}=81)$ found no significant correlation between adherence and the support of a significant other. ${ }^{34}$ National US survey results from physicians treating patients with schizophrenia who had extensive family contact $(n=171)$ and those with low family contact $(n=132)$ found that the groups did not differ significantly with respect to the duration of nonadherence or the frequency with which patients discontinued treatment or were hospitalized following a period of nonadherence. ${ }^{35}$ However, psychiatrists with patients who had high family contact were more likely to change medication dose in response to nonadherence episodes and were more likely to use psychological, behavioral, and family interventions in treating patients with high family contact. In contrast, psychiatrists with patients who had low family contact were more likely to prescribe an LAI antipsychotic rather than an oral medication or treatments that would require more frequent monitoring to ensure proper administration. ${ }^{35}$

The conflicting data with regard to the importance of family and social support suggest that closer management from health care professionals may be necessary for some patients with insufficient support systems to overcome issues with nonadherence. Furthermore, it has been shown that some patients' family members may oppose treatment with medica- tion, ${ }^{31}$ making third-party efforts necessary to educate and encourage acceptance of prescribed pharmacotherapy.

\section{Multidimensional treatment to improve adherence}

A working alliance between clinicians and patients has been shown to be a strong predictor of medication adherence. ${ }^{36}$ In a study of 763 Veterans Affairs patients with schizophrenia, patients enrolled in an ACT program were more than twice as likely to have good medication adherence (medicationpossession ratio $>80 \%$ ) compared with those who did not enroll. ${ }^{37}$ Another study evaluating 198 patients with schizophrenia found that those treated in an ACT program were significantly more likely to have adequate adherence ( $<20 \%$ missed medication days) compared with patients receiving standard clinical case management. ${ }^{38}$ In a study of 547 patients with a first episode of schizophrenia comparing adherence with an ACT program versus standard of care, the ACT group had a significantly lower incidence of "no outpatient visits" ( $4 \%$ versus $15 \%$, respectively; $P<0.001$ ), "treatment discontinued for $\geq 1$ month" ( $8 \%$ versus $22 \%$; $P<0.001)$, and "treatment stopped in spite of need" $(3 \%$ versus $15 \% ; P<0.001)$ after 1 year of follow-up. ${ }^{39}$ After 2 years of follow-up, the differences in these proxy adherence measures continued to be significant for "no outpatient visits" (7\% versus $31 \%$; $P<0.001$ ), but not for "treatment discontinued for $\geq 1$ month" ( $12 \%$ versus $14 \% ; P=0.06)$ or "treatment stopped in spite of need" ( $4 \%$ versus $6 \% ; P=0.3$ ). Patients in the ACT group of this study also had better control of positive and negative symptoms, had lower incidence of substance abuse, and were more likely to be living independently. Other studies of ACTs or similar team-treatment approaches have demonstrated positive effects on health status and hospitalizations in patients with schizophrenia but did not specifically evaluate patient adherence. ${ }^{40-44}$ Therefore, evidence supports the notion that multidisciplinary treatment teams can improve adherence and other associated outcomes for patients with schizophrenia.

Furthermore, data suggest that social workers and nurses have an important role to play in identifying and addressing barriers to adherence as part of a treatment-team framework. An enhanced-treatment intervention strategy was evaluated in 349 patients with schizophrenia treated through the US Veterans Administration. ${ }^{45}$ Research nurses interviewed patients at baseline about nine potential barriers to adherence: 1) memory problems, 2) problems with the medication regimen, 3) the patient's fear of medication, 4) adverse drug reactions, 5) denial of illness, 6) stigma of taking medications, 
7) lack of trust in the provider, 8) lack of social support, and 9) other barriers to adherence (anything not included in the previous eight items). After 6 months of treatment with tailored strategies designed to overcome adherence barriers identified in the baseline interview, patients receiving the enhanced intervention were nearly twice as likely to be adherent compared with patients receiving standard care (odds ratio 1.94, 95\% CI 1.08-3.48).

\section{Discussion}

In patients with schizophrenia, medication compliance is critical to optimal patient functioning and overall health. Nonadherence to antipsychotic medication regimens is associated with increased risk of hospitalizations and treatment costs. Factors that may contribute to nonadherence are related to the drug class and formulation used, patient-related factors (eg, anosognosia, access to health care, comorbid substance abuse), and family/social support. Inconsistent data on the effectiveness of patients' family/social support systems in improving medication adherence suggest that constructive involvement of health care professionals is important for optimizing adherence.

Overcoming nonadherence to medication in patients with schizophrenia is a complex issue that requires consideration of multiple factors that can have differing or additive effects. For example, one study found that treatment with an atypical antipsychotic (versus a typical antipsychotic) and presence of a patient guardian to facilitate drug taking were associated with four-fold and two-fold increases in the likelihood of patient adherence, respectively, but that the combined effect of having both factors was synergistic (a nearly ten-fold increase in the likelihood of adherence). ${ }^{5}$ This suggests that simply prescribing an atypical antipsychotic is insufficient to realize all the advantages associated with a well-chosen option.

A team approach to ensuring patient medication adherence is required, regardless of the efficacy and tolerability of the drug prescribed. Medications may be associated with significant adverse events, but such patient factors as cognitive impairment or sensitivity about the stigma of taking medications for a psychiatric illness may also be barriers to adherence. Other barriers to treatment adherence include issues with transportation, access to care, and ability to afford medication copayments. A team approach allows treatment team members an opportunity not only to address clinical issues but also to help the patient navigate the health care system, as well as overcome logistical obstacles to care. For patients experiencing anosognosia, one study ${ }^{29}$ concluded that initiation of LAI treatment, daily observation of medications, and psychoeducation of family members were more effective than patient psychological interventions for managing medication nonadherence. In my experience, these techniques can be helpful but should be considered on an individual basis after discussion with the full treatment team, the patient, and caregiver(s).

Data suggest that LAIs can help overcome patient nonadherence to oral formulations in observational or naturalistic trial settings. Although there is the potential for nonadherence in patients receiving LAIs, such nonadherence is immediately apparent because a treating physician must administer the injection, which allows the treatment team to proactively address missed doses. However, the potential benefits of prescribing LAIs to improve adherence remain largely unrealized because the majority $(>80 \%)$ of patients with schizophrenia receiving antipsychotic treatment do not receive LAI medication. ${ }^{23,25}$ Moreover, despite infrequent dosing, patients prescribed an LAI may have poor adherence due to patient-specific factors, such as embarrassment about the stigma associated with taking psychiatric medication or lack of health insurance. Patients may lack family involvement or social support, or such logistical issues as access to a provider or transportation may limit adherence in patients who are willing to take medication.

An important limitation of the available data concerning nonadherence in patients with schizophrenia is the inconsistency in results relative to trial design. RCTs are the gold standard for assessing treatment effectiveness because they are best suited for controlling potential confounding factors and for eliminating unintended treatment selection bias. However, RCTs may not be ideal for evaluating nonadherence because they do not adequately consider realworld factors. As such, observational (naturalistic) study designs may be more appropriate for evaluating outcomes related to nonadherence. This concept may explain why LAIs have been shown to be superior to oral formulations in observational studies but not RCTs. ${ }^{27}$

An integrated, multidisciplinary team approach to managing patients with schizophrenia, most notably through ACT teams, has been shown to improve patient outcomes. Through careful patient assessment, a social worker or nurse can identify and address potential barriers to optimizing patient adherence. An interesting finding was evidence suggesting that ACT programs improved adherence and outcomes in patients with first-episode psychosis, which suggests that ACT teams may be a valuable treatment option 
from the outset of treatment and not simply in patients with demonstrative nonadherence. Nonetheless, most studies of ACT have not focused specifically on treatment adherence as an outcome, making it difficult to draw conclusions about whether improvements are due to increasing adherence or improvements in other areas of care, such as the patient-specific and support-system issues described earlier. Additional studies of ACT and other treatment-team approaches in patients with schizophrenia are warranted and should include adherence as an outcome, with comparisons of adherence when different drug classes and formulations are prescribed.

The specific contribution of social workers to schizophreniatreatment teams also warrants further research. In my experience, social workers play an invaluable role in helping patients overcome challenges related to medication nonadherence. Social workers are specifically trained to help bridge the gap when patients require help resolving treatment problems, attaining support services, overcoming geographic challenges, addressing health disparities, and optimizing the patient-family relationship. However, there is currently a paucity of information in the scientific literature about the extent to which the efforts of social workers are able to enhance the achievement of treatment goals. As such, the treatment-team processes and structures that may be most beneficial to a given patient with schizophrenia remain unclear. Given the many confounding issues that can affect nonadherence in patients with schizophrenia and the inconclusive evidence for some factors (eg, typical versus atypical antipsychotics, LAIs versus oral formulations), the results from studies included in the current review are not necessarily generalizable to all clinical practice decisions. Rather, social workers should have awareness of the various factors that can influence nonadherence for generating educated, patient-specific decisions about treatment goals and options. It is important to note that different study types and patient subpopulations were used for exploring these factors in the current review, and the applicability of findings from these studies must be considered with caution on a case-bycase basis. In the future, it will be important for researchers to examine more closely how social workers and other treatment-team members can most effectively help patients overcome barriers associated with medication nonadherence at each step of the treatment process.

\section{Acknowledgments}

Editorial support for this article was provided by Jeffrey Coleman, MA, and Brett D Mahon, PhD, of C4 MedSolutions,
LLC (Yardley, PA), a CHC Group company. Funding for this support was provided by Otsuka America Pharmaceutical, Inc., and $\mathrm{H}$ Lundbeck A/S.

\section{Disclosure}

The author reports no conflicts of interest in this work.

\section{References}

1. Rummel-Kluge C, Schuster T, Peters S, Kissling W. Partial compliance with antipsychotic medication is common in patients with schizophrenia. Aust N Z J Psychiatry. 2008;42(5):382-388.

2. Hudson TJ, Owen RR, Thrush CR, et al. A pilot study of barriers to medication adherence in schizophrenia. J Clin Psychiatry. 2004;65(2): 211-216.

3. Cortesi PA, Mencacci C, Luigi F, et al. Compliance, persistence, costs and quality of life in young patients treated with antipsychotic drugs: results from the COMETA study. BMC Psychiatry. 2013;13:98.

4. Dilla T, Ciudad A, Alvarez M. Systematic review of the economic aspects of nonadherence to antipsychotic medication in patients with schizophrenia. Patient Prefer Adherence. 2013;7:275-284.

5. Farabee D, Shen H, Sanchez S. Program-level predictors of antipsychotic medication adherence among parolees. Int $J$ Offender Ther Comp Criminol. 2004;48(5):561-571.

6. Peng X, Ascher-Svanum H, Faries D, Conley RR, Schuh KJ. Decline in hospitalization risk and health care cost after initiation of depot antipsychotics in the treatment of schizophrenia. Clinicoecon Outcomes Res. 2011;3:9-14.

7. Rabinovitch M, Béchard-Evans L, Schmitz N, Joober R, Malla A. Early predictors of nonadherence to antipsychotic therapy in first-episode psychosis. Can J Psychiatry. 2009;54(1):28-35.

8. Boardman GH, McCann TV, Clark E. Accessing health care professionals about antipsychotic medication related concerns. Issues Ment Health Nurs. 2008;29(7):739-754.

9. Lang K, Meyers JL, Korn JR, et al. Medication adherence and hospitalization among patients with schizophrenia treated with antipsychotics. Psychiatr Serv. 2010;61(12):1239-1247.

10. DiBonaventura M, Gabriel S, Dupclay L, Gupta S, Kim E. A patient perspective of the impact of medication side effects on adherence: results of a cross-sectional nationwide survey of patients with schizophrenia. BMC Psychiatry. 2012;12:20.

11. Kotzè AM, van Delft WF, Roos JL. Continuity of care of outpatients with schizophrenia in Pretoria. SAfr J Psychiatr. 2010;16(3):80-83.

12. Bond GR, Drake RE, Mueser KT, Latimer E. Assertive community treatment for people with severe mental illness: critical ingredients and impact on patients. Dis Manage Health Outcomes. 2001;9(3): 141-159.

13. Moher D, Liberati A, Tetzlaff J, Altman DG, PRISMA Group. Preferred reporting items for systematic reviews and meta-analyses: the PRISMA statement. BMJ. 2009;339:b2535.

14. San L, Bernardo M, Gómez A, Martinez P, González B, Peña M. Socio-demographic, clinical and treatment characteristics of relapsing schizophrenic patients. Nord J Psychiatry. 2013;67(1):22-29.

15. Gilmer TP, Dolder CR, Lacro JP, et al. Adherence to treatment with antipsychotic medication and health care costs among Medicaid beneficiaries with schizophrenia. Am J Psychiatry. 2004;161(4): 692-699.

16. Marcus SC, Olfson M. Outpatient antipsychotic treatment and inpatient costs of schizophrenia. Schizophr Bull. 2008;34(1):173-180.

17. Becker MA, Young MS, Ochshorn E, Diamond RJ. The relationship of antipsychotic medication class and adherence with treatment outcomes and costs for Florida Medicaid beneficiaries with schizophrenia. Adm Policy Ment Health. 2007;34(3):307-314.

18. Knapp M, King D, Pugner K, Lapuerta P. Non-adherence to antipsychotic medication regimens: associations with resource use and costs. $\mathrm{Br} \mathrm{J}$ Psychiatry. 2004;184:509-516. 
19. Gianfrancesco FD, Rajagopalan K, Sajatovic M, Wang RH. Treatment adherence among patients with schizophrenia treated with atypical and typical antipsychotics. Psychiatry Res. 2006;144(2-3):177-189.

20. Menzin J, Boulanger L, Friedman M, Mackell J, Lloyd JR. Treatment adherence associated with conventional and atypical antipsychotics in a large state Medicaid program. Psychiatr Serv. 2003;54(5):719-723.

21. Dolder CR, Lacro JP, Dunn LB, Jeste DV. Antipsychotic medication adherence: is there a difference between typical and atypical agents? Am J Psychiatry. 2002;159(1):103-108.

22. Velligan DI, Weiden PJ, Sajatovic M, et al. The expert consensus guideline series: adherence problems in patients with serious and persistent mental illness. J Clin Psychiatry. 2009;70 Suppl 4:1-46; quiz 47-48.

23. West JC, Marcus SC, Wilk J, Countis LM, Regier DA, Olfson M. Use of depot antipsychotic medications for medication nonadherence in schizophrenia. Schizophr Bull. 2008;34(5):995-1001.

24. Zhu B, Ascher-Svanum H, Shi L, Faries D, Montgomery W, Marder SR. Time to discontinuation of depot and oral first-generation antipsychotics in the usual care of schizophrenia. Psychiatr Serv. 2008;59(3): 315-317.

25. Offord S, Wong B, Mirski D, Baker RA, Lin J. Healthcare resource usage of schizophrenia patients initiating long-acting injectable antipsychotics vs oral. J Med Econ. 2013;16(2):231-239.

26. Leucht C, Heres S, Kane JM, Kissling W, Davis JM, Leucht S. Oral versus depot antipsychotic drugs for schizophrenia - a critical systematic review and meta-analysis of randomised long-term trials. Schizophr Res. 2011;127(1-3):83-92.

27. Kirson NY, Weiden PJ, Yermakov S, et al. Efficacy and effectiveness of depot versus oral antipsychotics in schizophrenia: synthesizing results across different research designs. J Clin Psychiatry. 2013;74(6): $568-575$.

28. Purvis TL, Nelson LA, Elliott ES, et al. Outpatient adherence to risperidone long-acting injection following discharge from a state psychiatric hospital. Am J Pharm Benefits. 2011;3(5):284-290.

29. Olfson M, Marcus SC, Wilk J, West JC. Awareness of illness and nonadherence to antipsychotic medications among persons with schizophrenia. Psychiatr Serv. 2006;57(2):205-211.

30. Kim E, Gupta S, Bolge S, Chen CC, Whitehead R, Bates JA. Adherence and outcomes associated with copayment burden in schizophrenia: a cross-sectional survey. J Med Econ. 2010;13(2):185-192.

31. Kozuki Y, Schepp KG. Adherence and nonadherence to antipsychotic medications. Issues Ment Health Nurs. 2005;26(4):379-396.

32. Zeber JE, Grazier KL, Valenstein M, Blow FC, Lantz PM. Effect of a medication copayment increase in veterans with schizophrenia. Am J Manag Care. 2007;13(6 Pt 2):335-346.

33. Rabinovitch M, Cassidy C, Schmitz N, Joober R, Malla A. The influence of perceived social support on medication adherence in first-episode psychosis. Can J Psychiatry. 2013;58(1):59-65.

34. McCann TV, Lu S. Medication adherence and significant others' support of consumers with schizophrenia in Australia. Nurs Health Sci. 2009;11(3):228-234.

35. Wilk JE, West JC, Marcus SC, Countis L, Regier DA, Olfson M. Family contact and the management of medication non-adherence in schizophrenia. Community Ment Health J. 2008;44(5):377-380.
36. Weiss KA, Smith TE, Hull JW, Piper AC, Huppert JD. Predictors of risk of nonadherence in outpatients with schizophrenia and other psychotic disorders. Schizophr Bull. 2002;28(2):341-349.

37. Valenstein M, McCarthy JF, Ganoczy D, et al. Assertive community treatment in veterans affairs settings: impact on adherence to antipsychotic medication. Psychiatr Serv. 2013;64(5):445-451, 451. e1.

38. Manuel JI, Covell NH, Jackson CT, Essock SM. Does assertive community treatment increase medication adherence for people with co-occurring psychotic and substance use disorders? J Am Psychiatr Nurses Assoc. 2011;17(1):51-56.

39. Petersen L, Jeppesen P, Thorup A, et al. A randomised multicentre trial of integrated versus standard treatment for patients with a first episode of psychotic illness. BMJ. 2005;331(7517):602.

40. Aagaard J, Müller-Nielsen K. Clinical outcome of assertive community treatment (ACT) in a rural area in Denmark: a case-control study with a 2-year follow-up. Nord J Psychiatry. 2011;65(5):299-305.

41. Karow A, Reimer J, König HH, et al. Cost-effectiveness of 12-month therapeutic assertive community treatment as part of integrated care versus standard care in patients with schizophrenia treated with quetiapine immediate release (ACCESS trial). J Clin Psychiatry. 2012;73(3): e402-e408

42. McHugo GJ, Bebout RR, Harris M, et al. A randomized controlled trial of integrated versus parallel housing services for homeless adults with severe mental illness. Schizophr Bull. 2004;30(4):969-982.

43. Granholm E, Anthenelli R, Monteiro R, Sevcik J, Stoler M. Brief integrated outpatient dual-diagnosis treatment reduces psychiatric hospitalizations. Am J Addict. 2003;12(4):306-313.

44. Rodrigo C, Welgama S, Wijeratne T, Weligepola R, Rajapakse S, Jayananda G. A prospective cohort study on the role of nonspecialist staff in preventing relapses and improving clinic attendance of patients with schizophrenia. Indian J Psychiatry. 2013;55(1):74-76.

45. Hudson TJ, Owen RR, Thrush CR, Armitage TL, Thapa P. Guideline implementation and patient-tailoring strategies to improve medication adherence for schizophrenia. J Clin Psychiatry. 2008;69(1):74-80.

46. Chen J, Ascher-Svanum H, Nyhuis AW, et al. Reasons for continuing or discontinuing olanzapine in the treatment of schizophrenia from the perspectives of patients and clinicians. Patient Prefer Adherence. 2011;5:547-554.

47. Diaz E, Neuse E, Sullivan MC, Pearsall HR, Woods SW. Adherence to conventional and atypical antipsychotics after hospital discharge. J Clin Psychiatry. 2004;65(3):354-360.

48. McCann TV, Deans C, Clark E, Lu S. A comparative study of antipsychotic medication taking in people with schizophrenia. Int $J$ Ment Health Nurs. 2008;17(6):428-438.

49. McCann TV, Clark E, Lu S. Subjective side effects of antipsychotics and medication adherence in people with schizophrenia. $J A d v$ Nurs. 2009;65(3):534-543.

50. Stroup TS, McEvoy JP, Lieberman JA. Revised PORT recommendations. Schizophr Bull. 2004;30(3):609-611.
Patient Preference and Adherence

\section{Publish your work in this journal}

Patient Preference and Adherence is an international, peer-reviewed, open access journal focusing on the growing importance of patient preference and adherence throughout the therapeutic continuum. Patient satisfaction, acceptability, quality of life, compliance, persistence and their role in developing new therapeutic modalities and compounds to

\section{Dovepress}

optimize clinical outcomes for existing disease states are major areas of interest. This journal has been accepted for indexing on PubMed Central. The manuscript management system is completely online and includes a very quick and fair peer-review system. Visit http://www.dovepress.com/ testimonials.php to read real quotes from published authors. 